Nevşehir Bilim ve Teknoloji Dergisi (2019), 8(IMSMATEC Özel Sayı) 78-87

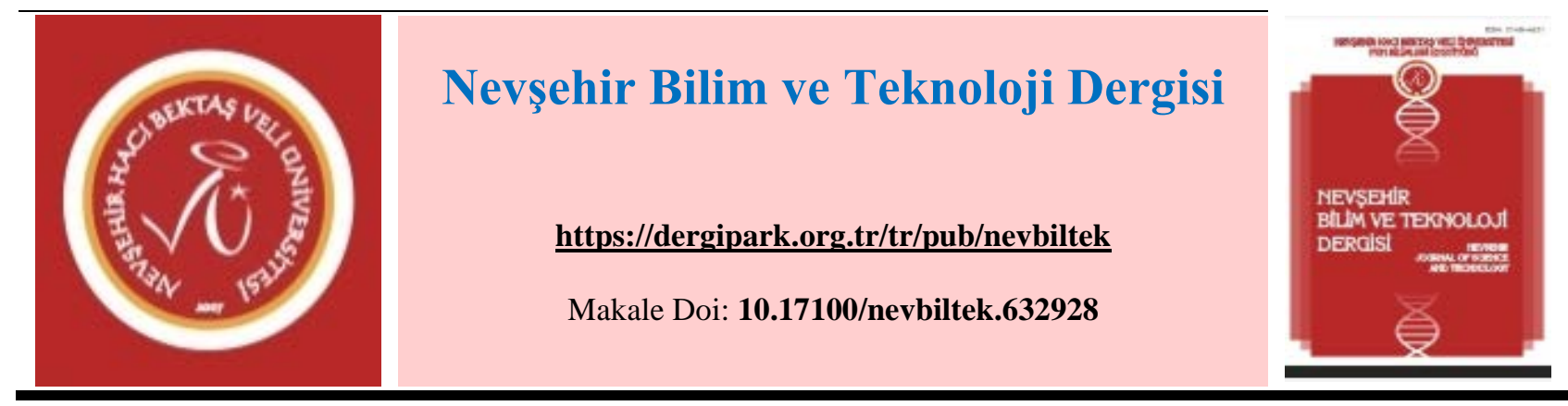

\title{
Rize yöresi obsidyeninin çimentonun hidratasyon ısısına etkisi
}

\author{
İlker USTABAŞ ${ }^{1}$, İhsan ÖMÜR ${ }^{1}$ \\ ${ }^{1}$ Recep Tayyip Erdoğan Üniversitesi, Mühendislik fakültesi, Inşaat Bölümü, Rize \\ ORCID ID:000-0003-0473-2543
}

Öz

Bu çalışmada, Rize yöresi obsidyeninin çimentonun hidratasyon ısısını nasıl etkilediği araştırılmıştır. Çimentoda yaygın olarak kullanılan mineral katkılardan uçucu kül ve yüksek firın cürufunun çimentodaki hidratasyon ısısına etkileri ile karşılaştırılmıştır. Obsidyen, uçucu kül ve yüksek fırın cüruflu çimentoların basınç dayanımları ölçülmüştür.

Çalışma sonucunda Rize yöresi obsidyeninin çimentonun hidratasyon 1sısını düşürmekte, basınç dayanımı açısından olumsuz bir etkiye neden olmamaktadır. Obsidyen, çimentoda hidratasyon ısısı ve basınç dayanımı açısından uçucu kül ve yüksek firın cürufuyla benzer etkilere göstermektedir.

Anahtar Kelimeler: Obsidyen, Uçucu kül, Yüksek firın cürufu, Hidratasyon ısısı.

\section{The effect of the obsidian of the rize region on the hydrating heat of cement}

\section{Abstract}

In this study, the effect of obsidian of Rize region on the hydration heat of cement was investigated. It was compared with the effects of fly ash and blast furnace slag on the hydration heat in cement. The compressive strengths of obsidian, fly ash and blast furnace slag cements were measured. As a result of this study, the obsidian of Rize decreases the hydration temperature of cement and does not cause a negative effect in terms of compressive strength. Obsidian shows similar effects with respect to fly ash and blast furnace slag in terms of heat and compressive strength of hydration in cement..

Keywords: Obsidian, Fly ash, Blast furnace slag, Hydration heat 
Nevşehir Bilim ve Teknoloji Dergisi (2019), 8(IMSMATEC Özel Sayı) 78-87

\section{Giriş}

Puzolanlar kendi başlarına bağlayıcıllğı olmayan ancak kireçle karşılaştıklarında bağlayıcılık kazanan malzemelerdir. Puzolanların kullanımı çok eski tarihlere kadar dayanmaktadır [1]. Çimentoda doğru olarak seçilen, işlenen ve kullanılan puzolanlar, maliyeti düşürür, betonun kalitesini artırır, betonu dışardan gelebilecek zararlı kimyasallara ve alkali silika reaksiyonlarına karşı korur [1,2] Çimentonun ana hidratasyon ürünlerinden klinkerin üretimi sırasında atmosfere $\mathrm{CO}_{2}$ salınır. $\mathrm{Bu}$ durum çevre açısından istenmeyen durumdur. Katkılı çimentolarda çimentoya katılan klinker miktarının daha az oranlarda kullanılmasını sağladığından katkılı çimentoların üretimi sırasında atmosfere $\mathrm{CO}_{2}$ salınımı daha az olur. Gerek betona sağladığı faydalar gerekse karbondioksit salınım miktarındaki azaltmasından dolayı puzolanlarla ilgili birçok bilimsel çalışma yapılmaktadır $[1,3,4,5,6,7,8]$. Suyun çimentoyla reaksiyonu sırasında tipik ekzotermik reaksiyonlar gibi açığa 1Sı çıkar [9]. Beton üretiminde açığa çıkan 1Sı belli değerleri aşması durumunda betona zarar verir. Hidratasyon ısının betona zararlarının önlenmesi için standartlar sınırlama ve kriterler koymuştur. TS 13515 standardı boyutları $90 \mathrm{~cm}$ kalınlığını geçen beton yapı elemanlarında taze betonda oluşacak en yüksek ısının $65{ }^{\circ} \mathrm{C}^{\prime} 1$ aşmaması gerektiği, donatılı betonlarda beton içi sıcaklıkla dış sıcaklık arasındaki farkın $25^{\circ} \mathrm{C}$, donatısız betonlarda $20^{\circ} \mathrm{C}$ 'yi aşmaması gerektiğini belirtmektedir [10]. Taze betonun sıcaklığı kontrol altında tutulmaması durumunda sertleşmiş betonda çatlaklar oluşur. Bu çatlaklar beton için zararlı oluşumlardır ve betonun servis ömrünün azalmasına yol açar. Özellikle kalın boyutlara sahip betonarme yapılarda düşük hidratasyon 1sılı çimentolar kullanmak betonu hidratasyon 1sısından oluşacak zararlardan korumak için uygulanan yöntemlerden biridir. TS 13515 (2014) standardı kalın boyutlara sahip betonarme yapılarda 7 günlük hidratasyon 1sıs1 60 cal/g hidratasyon ısısından daha düşük hidratasyon ısısına sahip çimentoları kullanmayı önermektedir. Çimentoda açığa çıkan 1S1 miktarı klinkerin yapısına, çimentonun bileşimine, mineral katkılara bağıdır. Mineral katkı kullanımı çimentonun hidratasyon ısısını düşürmede en yaygın olarak kullanılan yöntemler arasında yer almaktadır [9].

Uçucu kül ve yüksek firın cürufu çimentoda yaygın olarak kullanılan puzolanlardır. Uçucu kül termik santrallerinde kömürün yakılması sırasında, yüksek firın cürufu demir cevherinin yüksek firınlarda 1sitılması sonucu çıkan atığın hızlı şekilde soğutulması sonucunda oluşan atık maddelerdir. Bu çalışmada araştırılan volkanik cam diye bilinen obsidyen de puzolanik özelliği olan ancak literatürde bununla ilgili fazla bilimsel veriye rastlanmayan doğal bir maddedir. Obsidyen Rize ili İkizdere Büyük Yayla mevkiinde bolca bulunmaktadır. Bulunduğu bölgedeki obsidyen herhangi bir alanda kullanılmamaktadır. Obsidyenin camsı yapısından dolayı bulunduğu yerdeki bitki örtüsünü ve canlı yaşamını engellemektedir [11].

Bu çalışmada TS EN 197-1'e göre puzolan özelliği gösteren uçucu kül, yüksek firın cürufu ve obsidyenin çimentonun hidratasyon ısısını ve basınç dayanımını nasıl etkilediği araştırılmıştır.

\section{Materyal ve Metot}

Bu deneysel araştırma kapsamında uçucu kül, yüksek fırın cürufu ve obsidyen ilaveli çimentolarda TS EN 1969'a göre hidratasyon ısıları ölçülmüştür. Uçucu kül, yüksek firın cürufu ve obsidyen ilaveli çimentolarla üretilen harç numunelerde eğilme ve basınç dayanımları tespit edilmiştir.

Çalışmada, Ünye Çimento Fabrikası'nın CEM I 42,5 R tipi $50 \mathrm{~kg}$ paketlenmiş torba halindeki çimentosu kullanılmıştır. Çalışmada kullanılan uçucu kül (Uk), Tunçbilek Termik Santrali'nden, yüksek fırın cürufu (Yfc) ise Karabük Demir Çelik Fabrikası'nın cürufu olup Akçansa Çimento Fabrikası'ndan temin edilmiştir. Bağlayıcılara ait kimyasal bileşim ve puzolanlara ait reaktif silis içerikleri Tablo 1'de görülmektedir. 
Nevşehir Bilim ve Teknoloji Dergisi (2019), 8(IMSMATEC Özel Sayı) 78-87

Tablo 1. Çalışmada kullanılan çimento, obsidyen, uçucu kül ve yüksek firın cürufunun kimyasal bileşimi [11]

\begin{tabular}{lllll}
\hline & Çimento & Obsidyen & Uçucu kül & $\begin{array}{l}\text { Yüksek } \\
\text { firn cürufu }\end{array}$ \\
\hline $\mathbf{C a O}$ & 64,60 & 0,87 & 4,5 & 35,30 \\
$\mathbf{S i O}_{2}$ & 19,30 & 74,10 & 52,70 & 38,60 \\
$\mathbf{A l}_{2} \mathbf{O}_{3}$ & 5,17 & 13,80 & 18,00 & 11,40 \\
$\mathbf{F e}_{2} \mathbf{O}_{3}$ & 3,55 & 1,43 & 12,60 & 0,58 \\
$\mathbf{M g O}$ & 1,05 & 0,14 & 4,79 & 7,92 \\
$\mathbf{K}_{\mathbf{2}} \mathbf{O}$ & 1,16 & 4,88 & 1,87 & 1,45 \\
$\mathbf{N a}_{2} \mathbf{O}$ & 0,46 & 4,08 & 0,74 & 0,29 \\
$\mathbf{P}_{\mathbf{2}} \mathbf{O}_{\mathbf{5}}$ & 0,077 & 0,015 & 0,126 & 0,003 \\
$\mathbf{S O}_{3}$ & 2,860 & 0,005 & 1,64 & 3,43 \\
$\mathbf{T i O}_{2}$ & 0,14 & 0,14 & 0,76 & 0,44 \\
$\mathbf{S r}$ & 0,009 & 0,014 & 0,026 & 0,058 \\
$\mathbf{C r} \mathbf{O}_{3}$ & - & 0,07 & 0,10 & - \\
$\mathbf{M n O}$ & 0,23 & 0,06 & 0,15 & 1,40 \\
$\mathbf{L O I}$ & 2,81 & 0,03 & 1,47 & 1,08 \\
$\mathbf{R e a k t i f}$ & & 40,13 & 49,48 & 40,74 \\
silika içeriği & & & & \\
& & & 99,56 & 100,77 \\
TOPLAM & 101,45 & 99,55 & &
\end{tabular}

Şekil 1'te Rize İkizdere mevkiindeki yığıntı şeklinde bulunan obsidyenler görülmektedir. İncelemenin yapıldığı bu arazide oldukça kalın ve geniş araziye yayılmış masif ve döküntü şeklinde obsidyenler mevcuttur. Şekil 1'te görülen obsidyenler tıpkı kırık cam gibidir ve oldukça keskindirler. Obsidyenin arazideki durumu insan ve hayvanın bu bölgede dolaşmasını tehlikeye düşürmekte bitki yetişmesini engelleyecek türdendir.

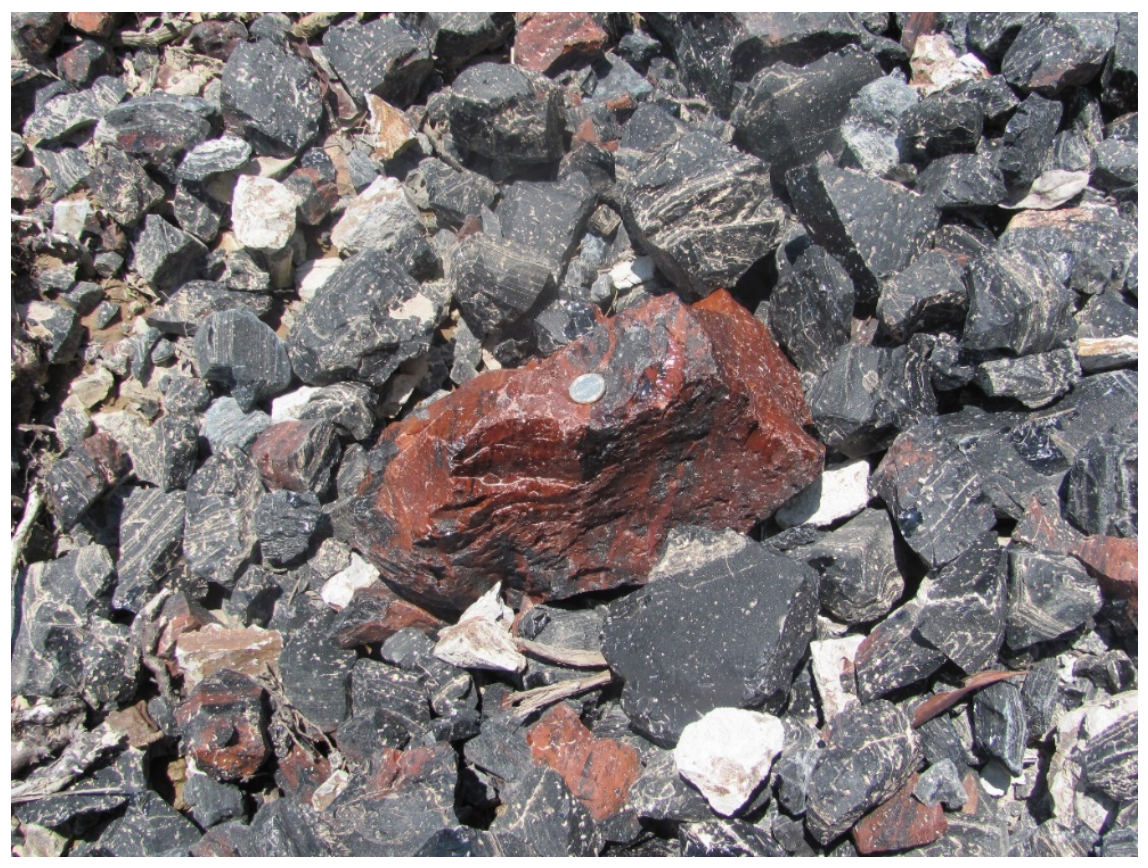

Şekil 1. Arazide obsidyen görüntüsü

Şekil 2'de görünen kaplarla araziden toplanan obsidyenler laboratuvarda çeneli kırıcılarda kırılıp bilyeli değirmenlerde öğütüldükten sonra çimentoya puzolan olarak katılmıştır. 
Nevşehir Bilim ve Teknoloji Dergisi (2019), 8(IMSMATEC Özel Sayı) 78-87

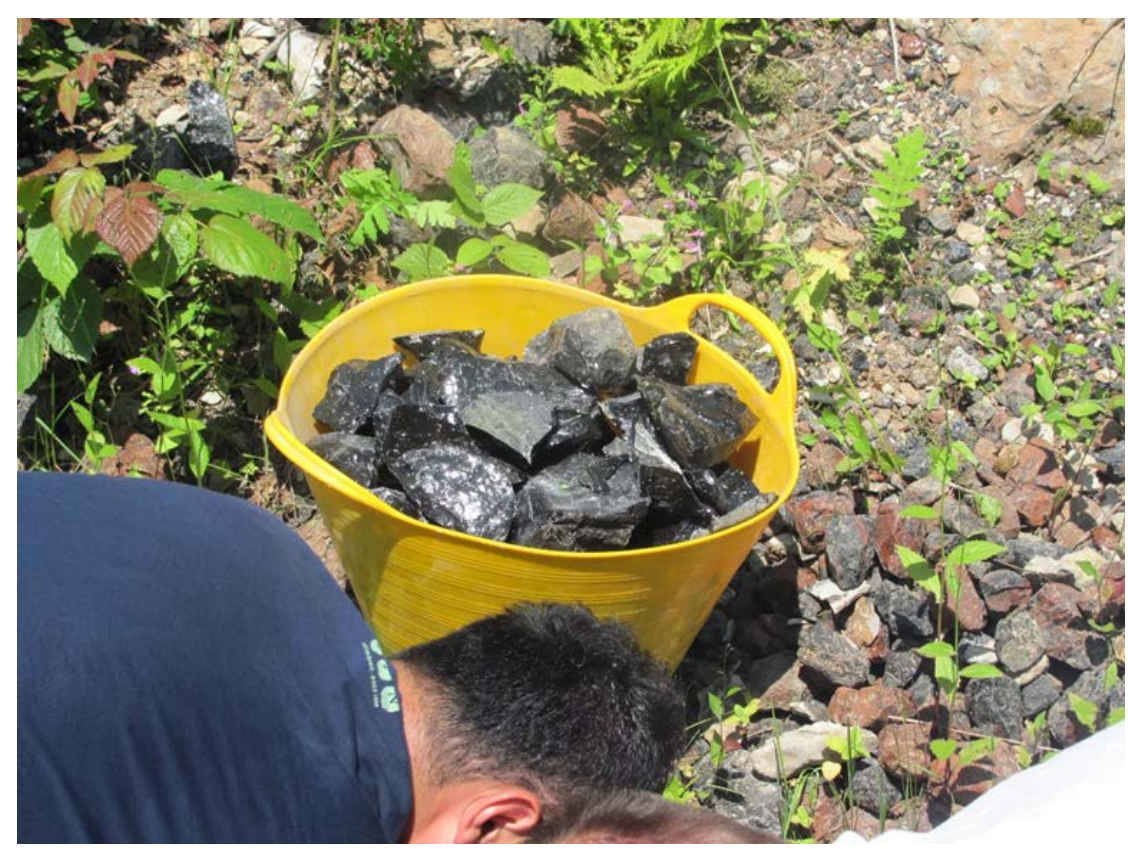

Şekil 2. Araziden obsidyenin toplanması

Şekil 3'teki XRD analizinden obsidyenin tipik amorf yapıya sahip bir madde olduğu anlaşılmaktadır. Amorf yapıılı, silis içeriği yüksek maddeler çimentoda puzolanik özellik gösteren maddeler arasında yer alırlar.
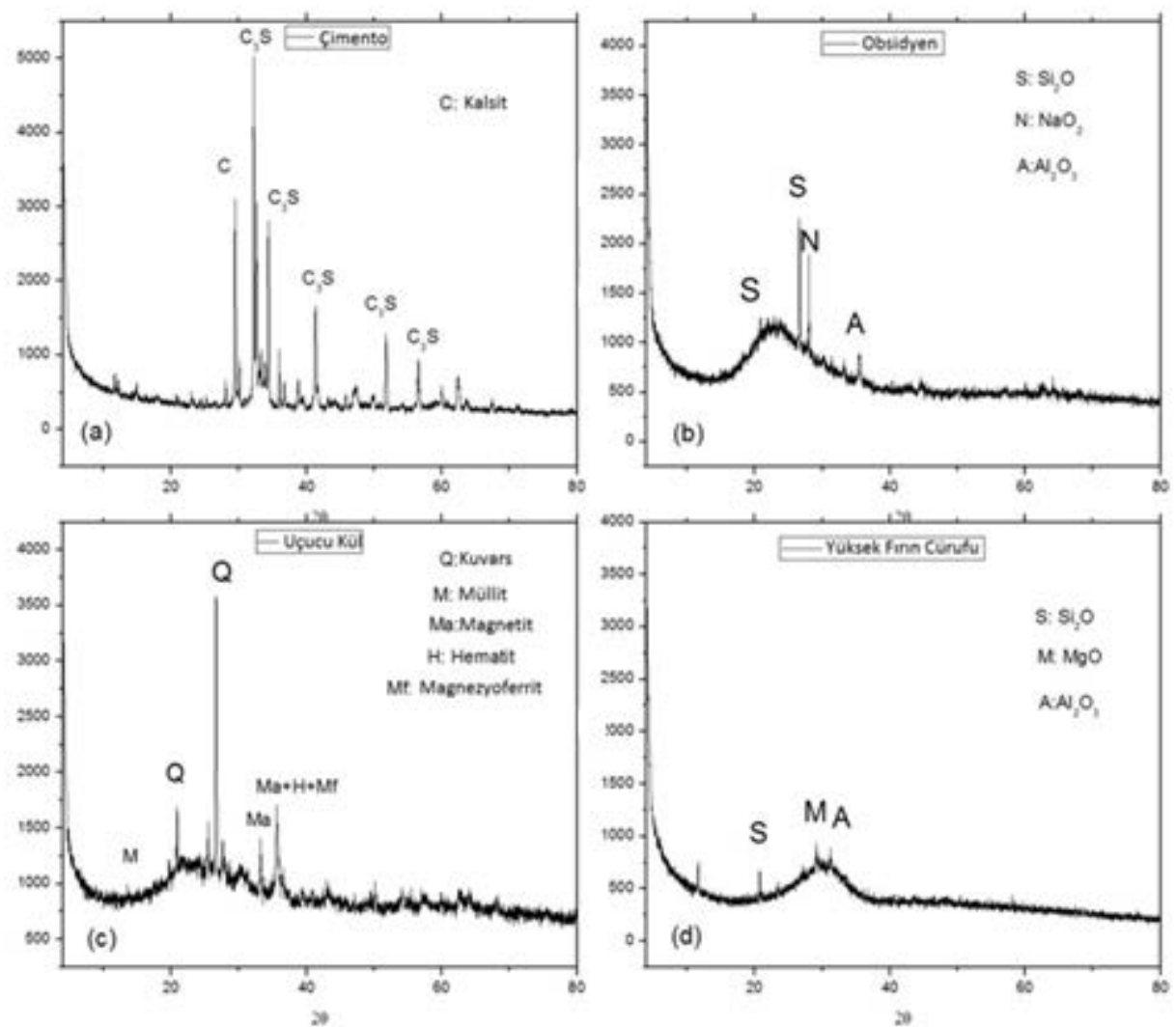

Şekil 3. Çimento, obsidyen, uçucu kül ve yüksek firın cürufunun XRD analizleri [11]

TS EN 196-9 ise yarı adyabatik yöntemle çimentonun hidratasyon ısısının tayininde 360 gram çimento, 180 gram su ve 1035 gram CEN standart kumu karıştırılarak numune hazırlanmaktadır. Toplam malzeme miktarı 1575 gram 
olmakta ve kalorimetrede biri referans, diğeri ölçüm numunesi olmak üzere iki numune üzerinden çimentoların hidratasyon sıcaklıkları ölçülmektedir. Her sıcaklık okumasında numunenin sıcaklık artışı ( $\theta \mathrm{t}$ ), numunenin sıcaklığı (Ts) ve referans kalorimetredeki numunenin sıcaklığı (Tr) arasındaki farktan Hidratasyon 1sısı (Q) aşağıdaki bağıntıdan hesaplanmaktadır.

$$
\mathrm{Q}=\frac{\mathrm{c}}{\mathrm{m}_{\mathrm{c}}} \theta_{\mathrm{t}}+\frac{1}{\mathrm{~m}_{\mathrm{c}}} \sum_{\mathrm{i}=1}^{\mathrm{i}=1} \overline{\alpha \mathrm{i}} \times \overline{\theta \mathrm{i}} x \Delta \mathrm{t}_{\mathrm{i}}(1)
$$

Bağıntıdaki mc deney numunesinin içerdiği çimento kütlesini (gram), t hidratasyon süresini (saat), c kalorimetrenin ısıl kapasitesini (J.K-1) ve $\alpha$ kalorimetrenin 1sıl kaybı katsayısını (J.h-1.K-1) göstermektedir.

Obsidyen, uçucu kül (uk) ve yüksek fırın cürufu (yfc) ilaveli çimentoların eğilme ve basınç dayanımları TS EN 196-1'e göre ölçülmüştür. TS EN 196-1'e göre 450 gram çimento, 225 su ve 1350 gram standart kum karışımından 40x40x160 mm ölçülere sahip prizmatik harç numuneler hazırlanmakta ve bu harç numunelere basınç testleri uygulanarak çimentoların basınç dayanımları hesaplanmaktadır.

\section{Bulgular}

TS EN 196-9'a göre hidratasyon 1sısı ölçülen çimentolarda obsidyen uçucu kül ve yüksek firın cürufu \%20, $\% 30$ ve $\% 50$ oranlarında çimentoya ikame edildi.

Şekil 4'te katkı içermeyen çimentoda TS EN 196-9 yöntemine göre ölçülen 160 saatlik hidratasyon 1sısı ve bu süre boyunca çimento harcındaki sıcaklık değişimi görülmektedir. Şekil 4'teki sürekli artış gösteren eğri çimentonun hidratasyon 1sısını, belli süre artıp sonra azalan eğri ise çimento hamurundaki sıcaklık değişimini göstermektedir.

Hidratasyon Isıs1 (J/g)

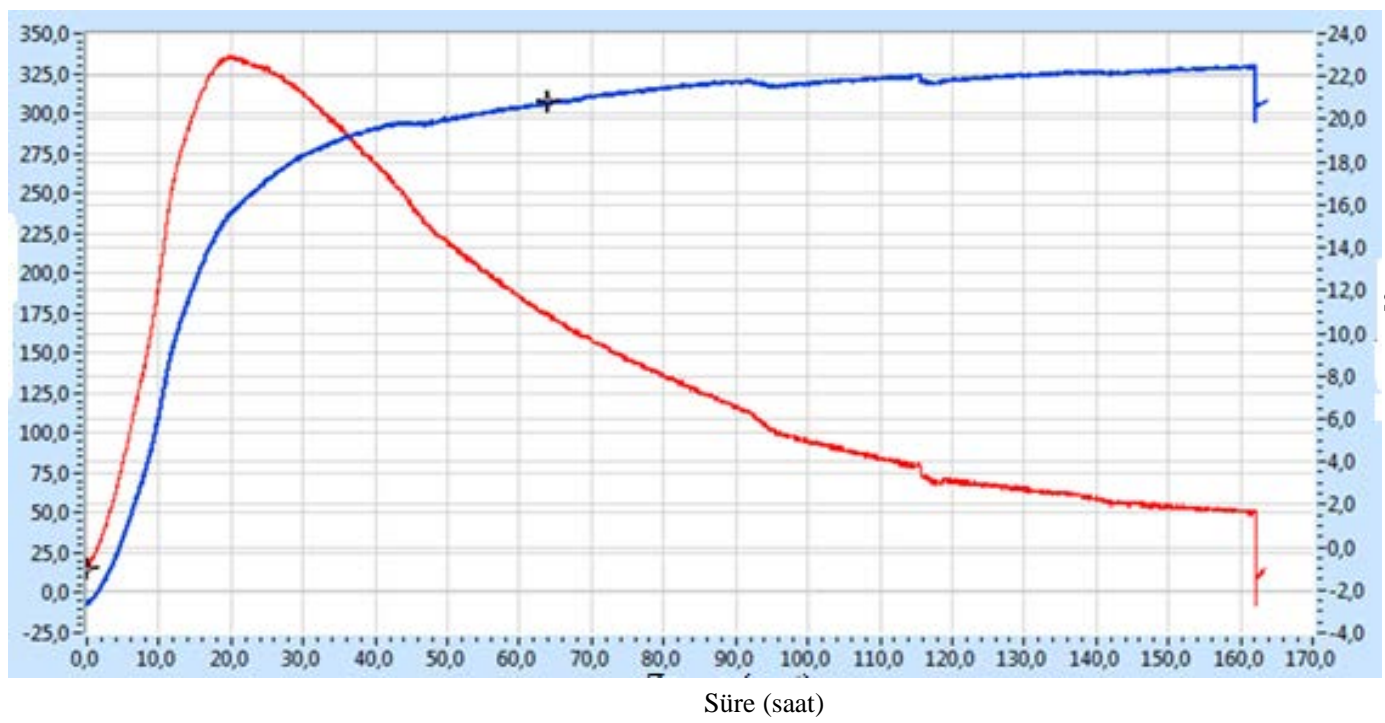

Şekil 4. Çimentoda TS EN 196-9'a göre hidratasyon ısısının ölçümü

Şekil 5'te Şekil 4'te görülen grafiklerden elde edilen çimento ve 60 dakika öğütülmüş obsidyenin \%20, \%30 ve \%50 oranında ilaveli çimentolarda TS EN 196-9'a göre 41. ve 160. saatlerde hesaplanan hidratasyon 1sıları görülmektedir. Şekil 5'te \%20 oranında 60 dakika öğütülmüş obsidyen ilaveli çimentoda 41. saatteki hidratasyon 1Sısı $285 \mathrm{~J} / \mathrm{g}$ ve 160. saatteki hidratasyon ısısının $325 \mathrm{~J} / \mathrm{g}$, \%30 oranında 60 dakika öğütülmüş obsidyen ilaveli çimentoda 41. saatteki hidratasyon 1Sısı $200 \mathrm{~J} / \mathrm{g}$ ve 160. saatteki hidratasyon 1sısının $300 \mathrm{~J} / \mathrm{g}, \% 50$ oranında 60 dakika öğütülmüş 
Nevşehir Bilim ve Teknoloji Dergisi (2019), 8(IMSMATEC Özel Sayı) 78-87

obsidyen ilaveli çimentoda 41. saatteki hidratasyon 1Sısı $150 \mathrm{~J} / \mathrm{g}$ ve 160 . saatteki hidratasyon 1sısının $250 \mathrm{~J} / \mathrm{g}$ olarak ölçüldüğ̈̈ görülmektedir.

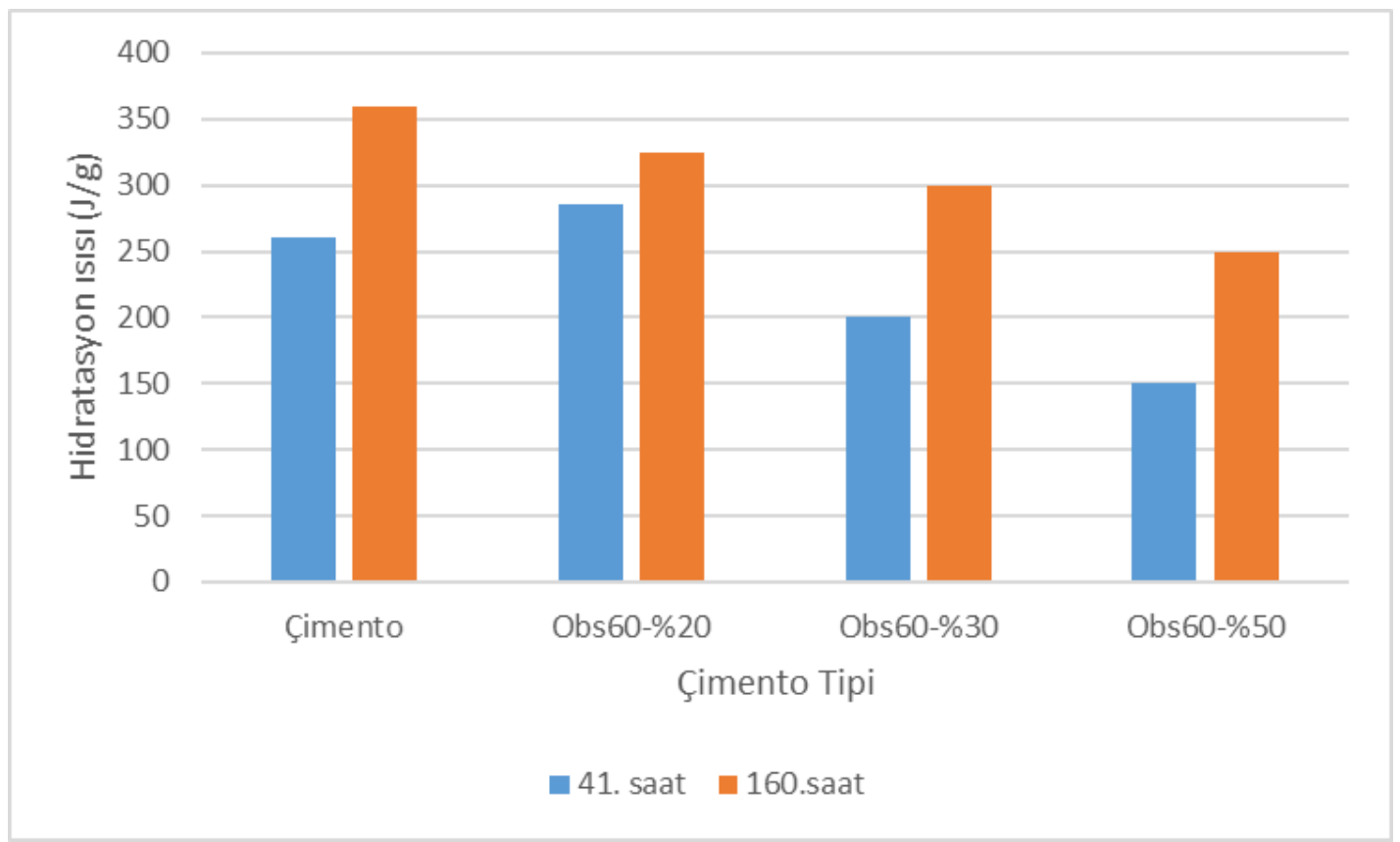

Şekil 5. 60 dakika öğütülmüş $\% 20, \% 30$ ve $\% 50$ oranında obsidyen ilaveli çimentolarda ölçülen hidratasyon ısıları

Şekil 6'da \% 20 oranında yüksek firın cürufu ilaveli çimentoda 41. saatteki hidratasyon 1sıs1 $160 \mathrm{~J} / \mathrm{g}$ ve 160 . saatteki hidratasyon 1 sısının $330 \mathrm{~J} / \mathrm{g}$, \% 30 oranında yüksek firın cürufu ilaveli çimentoda 41. saatteki hidratasyon 1sısı $140 \mathrm{~J} / \mathrm{g}$ ve 160. saatteki hidratasyon ısısının $270 \mathrm{~J} / \mathrm{g}, \% 50$ oranında yüksek firın cürufu ilaveli çimentoda 41. saatteki hidratasyon 1 sısı $160 \mathrm{~J} / \mathrm{g}$ ve 160. saatteki hidratasyon 1sısının $280 \mathrm{~J} / \mathrm{g}$ olarak ölçüldüğü görülmektedir.

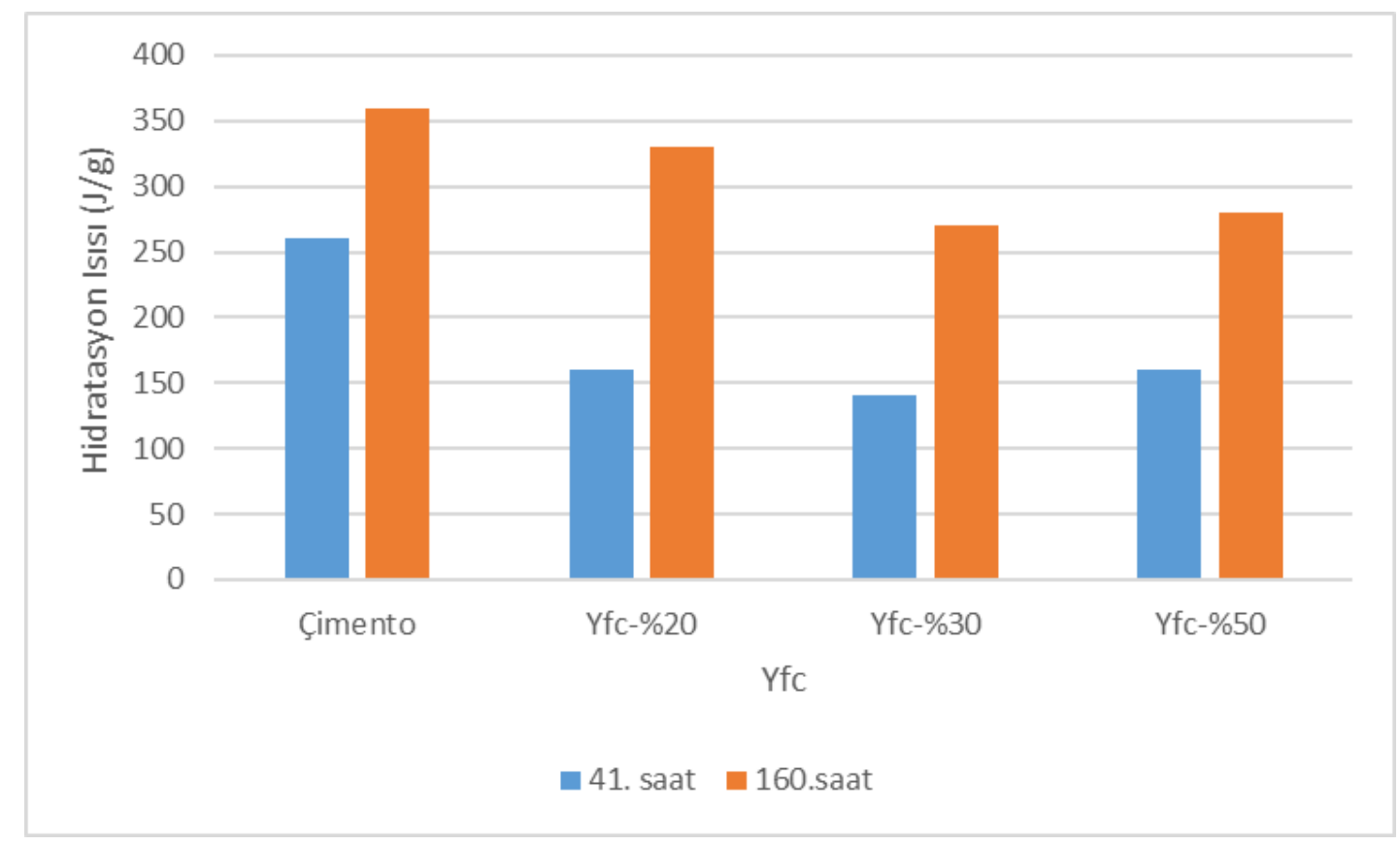

Şekil 6. $\% 20, \% 30$ ve $\% 50$ oranında yfc ilaveli çimentolarda ölçülen hidratasyon ısıları

Şekil 7'de \% 20 oranında uçucu kül ilaveli çimentoda 41. saatteki hidratasyon 1sısı $290 \mathrm{~J} / \mathrm{g}$ ve 160. saatteki hidratasyon 1sısının $365 \mathrm{~J} / \mathrm{g}$, \% 30 oranında uçucu kül ilaveli çimentoda 41. saatteki hidratasyon 1sısı $195 \mathrm{~J} / \mathrm{g}$ ve 160. 
Nevşehir Bilim ve Teknoloji Dergisi (2019), 8(IMSMATEC Özel Sayı) 78-87

saatteki hidratasyon ısısının $325 \mathrm{~J} / \mathrm{g}$, \% 50 oranında uçucu kül ilaveli çimentoda 41 . saatteki hidratasyon 1Sısı $110 \mathrm{~J} / \mathrm{g}$ ve 160. saatteki hidratasyon ısısının $235 \mathrm{~J} / \mathrm{g}$ olarak ölçüldüğü görülmektedir.

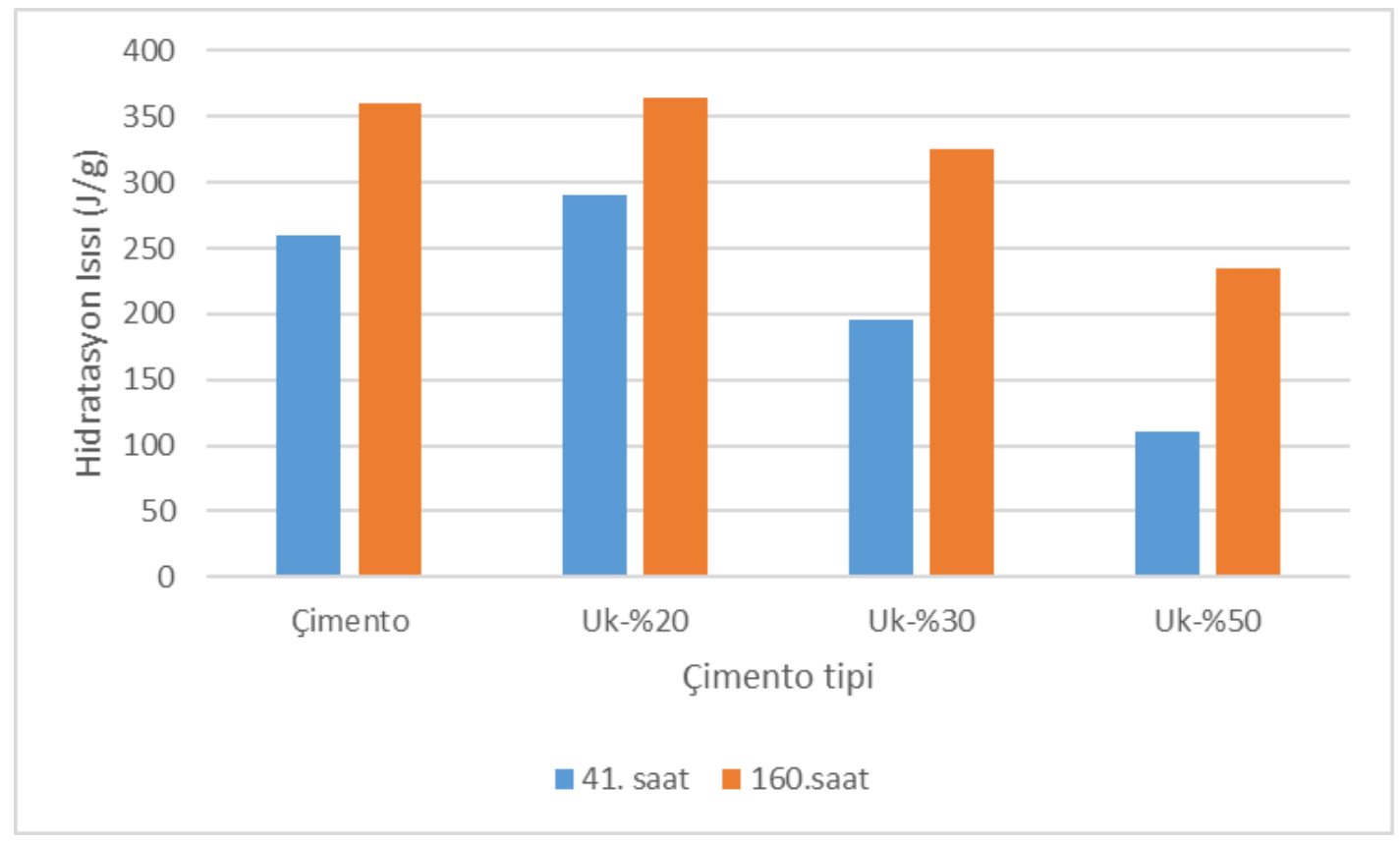

Şekil 7. \%20, \%30 ve \%50 oranında uk ilaveli çimentolarda ölçülen hidratasyon ısıları

Şekil 8'de katkı içermeyen çimentonun 41 ve 160 . saatteki hidratasyon 1sısının en fazla olduğu görülmektedir. Şekil 8'de \%50 obsidyen, uk ve yfc ilaveli çimentoların hidratasyon 1sılarının katkı içermeyen çimentolardan daha az olduğu görülmektedir. Şekil 8'de obsidyenli çimentonun hidratasyon ısılarının yfc ve uk ilaveli çimentolarla oldukça yakın değerlerde olduğu görülmektedir.

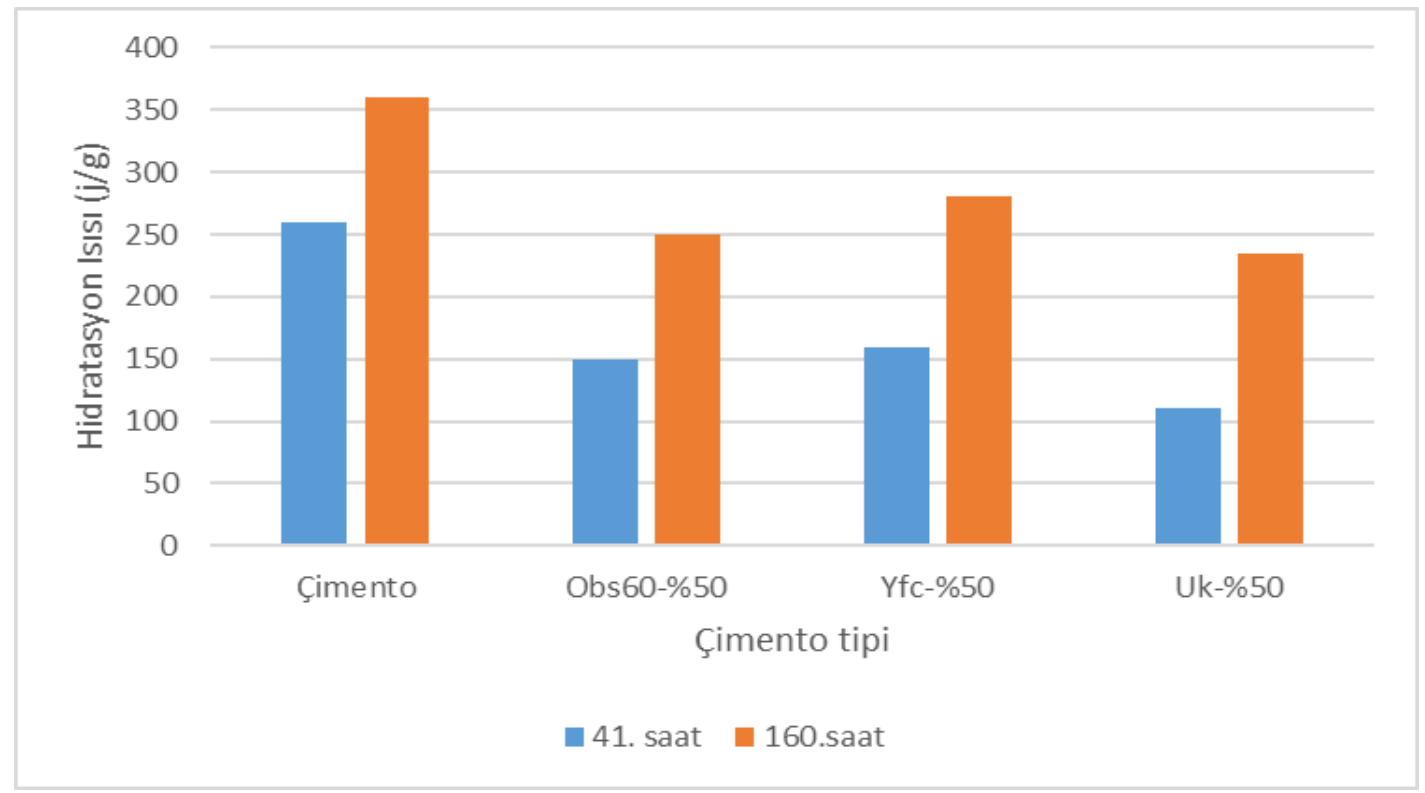

Şekil 8. Çimento ve $\% 50$ oranında obsidyen, yfc ve uk ilaveli çimentolarda ölçülen hidratasyon ısıları

Şekil 9'da CEM I 42,5 R tipi çimento ve bu çimentoya \%10, \%20,\%30 ve \%40 oranında 60 dakika öğütülmüş obsidyen katılmış çimento ile TS EN 196-1'e göre hazırlanan harç numunelerden elde edilen basınç dayanımları görülmektedir. Şekil 9'da çimentoya obsidyen katkı oranı arttıkça basınç dayanımlarında azalma olmuştur. 
Nevşehir Bilim ve Teknoloji Dergisi (2019), 8(IMSMATEC Özel Sayı) 78-87

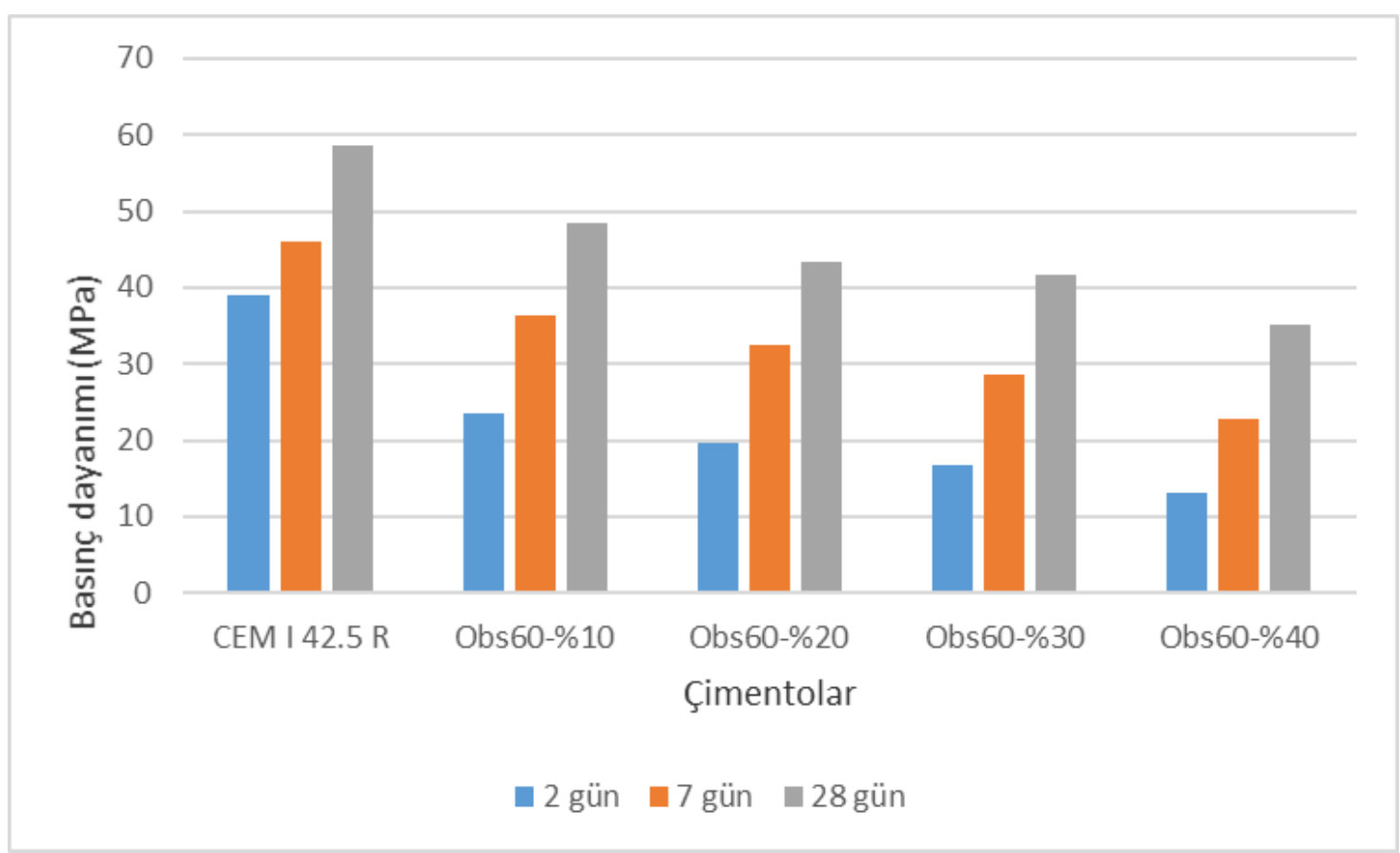

Şekil 9. Çimento ve obsidyen ilaveli çimentolarda TS EN 196-1'e göre ölçülen basınç dayanımları

Şekil 10'te CEM I 42,5 R çimentosu ve bu çimentoya \%40 oranında obsidyen, uçucu kül ve yüksek firın cürufu katılarak oluşturulan çimentolar ile TS EN 196-1'e göre hazırlanan harç numunelerinden elde edilen basınç dayanımları görülmektedir. Şekil 10'da en yüksek basınç dayanımı CEM I 42,5R çimentosunda olduğu bunu sırasıyla yüksek firın cürufu, obsidyen ve uçucu kül ilaveli çimentolar takip etmiştir. Obsidyen katkılı çimentolar basınç dayanımı açısından puzolan katkı oranı artıkça dayanım azalması yönünden yüksek firın cürufu ve uçucu kül katkılı çimentolarla benzer davranış göstermiştir.

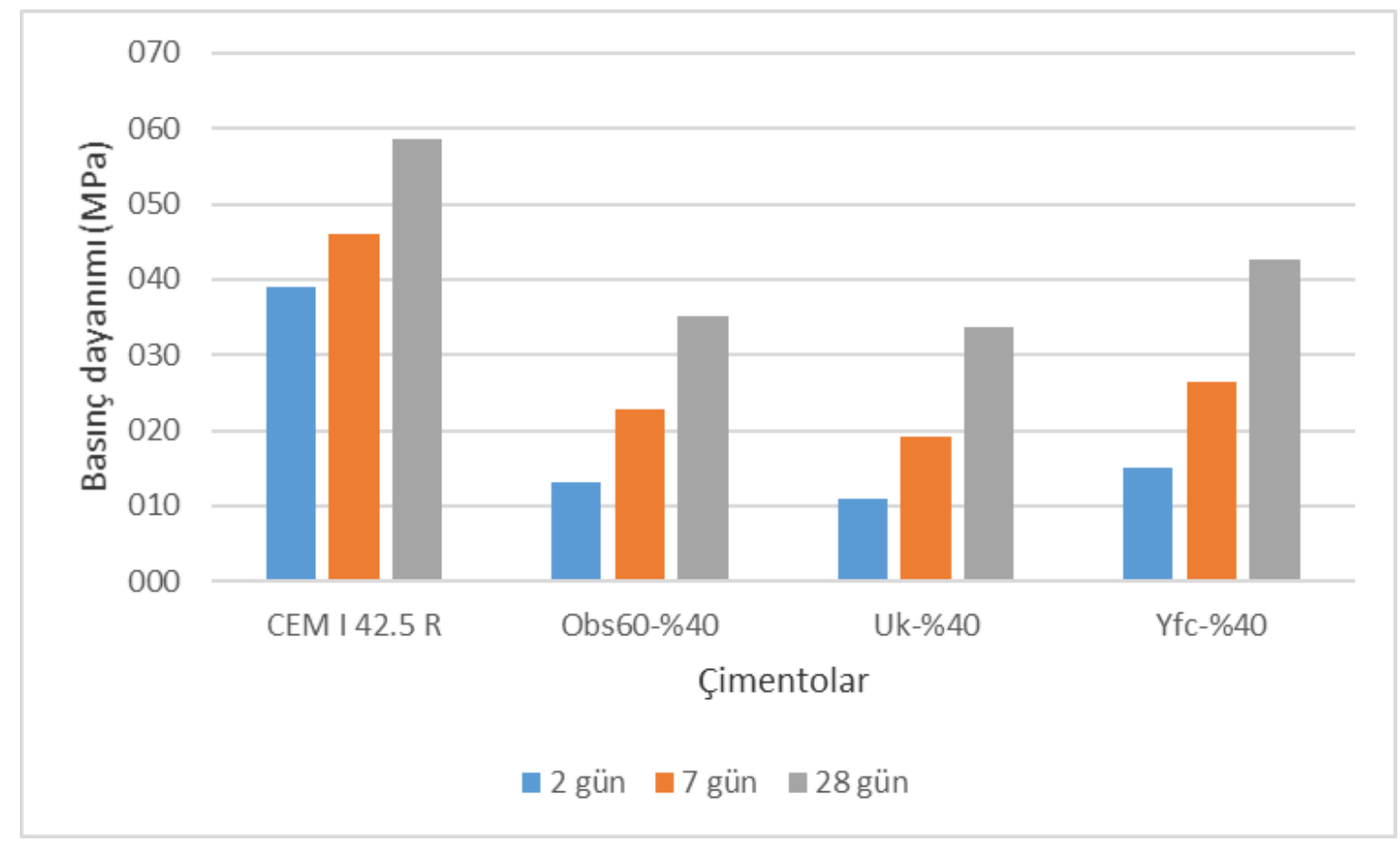

Şekil 10. Çimento ve \%40 obsidyen, uk ve yfc ilaveli çimentolarda TS EN 196-1'e göre ölçülen basınç dayanımları 


\section{Tartışma ve Sonuç}

Bu çalışmada yapılan TS EN 196-9'a göre çimentonun hidratasyon 1sısı ölçümlerinde çimentoya, obsidyen, uçucu kül ve yüksek firını cürufu ilave miktarı artıkça çimentonun hidratasyon 1sısının düştüğü görülmüştür. Erdogan (2013) ve Han (2017) çalışmalarında kullandıkları puzolanların bu çalışmadaki puzolanlara benzer şekilde hidratasyon ısısını düşürdüğünü belirtmişlerdir [1,12]. Literatürde TS EN 196-9 ile 41. saat hidratasyon 1sısı TS EN 196-8’e göre kimyasal yöntemle ölçülen hidratasyon ısısına eşit olduğu belirtilmektedir [13]. Bu çalışmada kullanılan çimentonun 41.saatteki hidratasyon ısısı 250 j/g değeri Erdoğanın çalışmasında kullandığı çimentonun hidratasyon ısısına eşittir [1]. Han vd. (2017) ölçtükleri yüksek firın cüruflu ve uçucu küllü çimentoların hidratasyon ısıları bu çalışmaya benzer değerlerde ölçtüler. Baran ve Pichniarczyk (2017) CEM I 42,5 R çimentosunda 374 ile 404 j/g arasında değerler hesapladı. Bu değerlerin bu çalışmadaki değerlerle uyumlu olduğu görülmektedir. Merzouki vd. (2013) 140 saatten sonraki hidratayon 1sılarında cürufun hidratasyon 1sısını düşürdüğünü belirtmektedir. Erdoğan Bu çalışmada da obsidyen, uçucu kül ve yüksek firın cürufunun çimentoya katılma oranı arttıkça çimentonun hidratasyon isısında azalma meydana gelmiştir. Bu çalışmadaki çimentolarla hesaplanan basınç dayanımları kıyaslandığında Rize yöresi obsidyeni çimentonun basınç dayanımına uçucu kül ve yüksek firın cürufuyla benzer etki göstermiştir.

Bu çalışmada aşağıda belirtilen hususlar tespit edilmiştir.

1. Rize yöresi obsidyeni çimentonun hidratasyon 1sısını düşürmektedir.

2. Obsidyenin hidratasyon 1sısı bakımından çimentoda uçucu kül ve yüksek firın cürufu ile benzer özellik göstermiştir.

3. Rize yöresi obsidyeni basınç dayanımı açısından çimentoda yüksek fırın cürufu ve uçucu küle yakın değerlere sahiptir. Obsidyen çimentoda puzolan olarak kullanılması durumda basınç dayanımı açısından zararlı bir etkiye sahip değildir.

\section{Teşekkür}

214M023 proje nolu “Farklı İnceliğe SahipUçucu Kül, Yüksek Fırın Cürufu ve Öğütülmüş Obsidyen Katkılı Çimentoların Puzolanik Aktivitesi, Hidratasyon Isısının Tayini ve Yapay Sinir Ağlarıyla Optimum Puzolan Katkı Oranının Belirlenmesi” isimli projesi ile bu çalışmaya desteklerinden dolayı TÜBiTAK'a teşekkür ederiz.

\section{Kaynaklar}

[1] Erdoğan, S.T., Sağlık, A.Ü. 2013. "Early-age activation of cement pastes and mortars containing ground perlite as a pozzolan”, Cement \& Concrete Composites, 38, 29-39.

[2] Mielenz RC, Greene KT, Schieltz NC. Natural pozzolans for concrete. Econ Geol 1951;46:311-28.

[3] Scholer, A., Lothenbach, B., Winnefeld, F., Zajac, M., 2015. "Hydration of quaternary Portland cement blends containing blast-furnace slag, siliceous fly ash and limestone powder”, Cement \& Concrete Composites, 55, 374-382.

[4] Uzal B., Turanlı, L., Yücel, H., Göncüoğlu, M.C., Çulfaz, A. 2010. "Pozzolanic activity of clinoptilolite: A comparative study with silica fume, fly ash and a non-zeolitic natural pozzolan”, Cement and Concrete Research, 40, 398-404.

[5] Caputo, D., Liguori, B., Colella, C. 2008. "Some advances in understanding the pozzolanic activity of zeolites: the effect of zeolite structure”, Cement \& Concrete Composites, 30, 455-462.

[6] Marjanović, M., Komljenović, Z., Baščarević, V., Nikolić, R., Petrović, N. 2015. "Physical-mechanical and microstructural properties of alkali-activated fly ash-blast furnaceslag blends”, Ceramics International, 41, 14211435. 
[7] İlker Ustabaş, Effect of mineral additive use on permeation properties of concrete and the relationship between permeation and carbonation, (2018) Turkish Journal of Materials, Turk. J. Mater. Vol: 3 No: 1 Page: 38-52

[8] İlker Ustabaş, Şakir Erdoğdu, Performance of mortars incorporating fly ash, silica fume, blast furnace slag at different temperature in magnesium sulfate solution, (2016), Turkish Journal of Materials, Turk. J. Mater. Vol: 1 No: 1 Page: $1-14$

[9] Baran, T., Pichniarczyk, P. 2017. "Correlation factor between heat of hydration and compressive strength of common cement”, Construction and Building Materials, 150, 321-332.

[10] TS 13515, TS EN 206’nın uygulamasına yönelik tamamlayıcı standard, Türk standardı, 2014.

[11] Ilker Ustabas, Ayberk Kaya, Comparing the pozzolanic activity properties of obsidian to those of fly ash and blast furnace slag, Construction and Building Materials 164 (2018) 297-307.

[12] Han, F., He, X., Zhang, Z., Liu, J., 2017. "Hydration heat of slag or fly ash in the composite binder at different temperatures”, Thermochimica Acta, 655, 202-210.

[13] TS EN 197-1, 2012, Çimento

\section{Extended abstract \\ Introduction}

Pozzolans are materials that do not bind on their own but gain binding when faced with lime.The use of pozzolans dates back to ancient times. Correctly selected, processed and used pozzolans in cement reduce the cost, increase the quality of concrete, protect concrete against harmful chemicals and alkali silica reactions.Heat emerges as typical exothermic reactions during the reaction of water with cement.If the heat produced in concrete production exceeds certain values, it will damage the concrete. Fly ash and blast furnace slag are pozzolans commonly used in cement.In this study, obsidian known as volcanic glass is a natural substance with pozzolanic feature but not much scientific data related to it in literature.

In this study, it was investigated how fly ash, blast furnace slag and obsidian which have puzolan properties affect the hydration heat and compressive strength of cement according to TS EN 197-1.

\section{Method}

Hydration temperatures of fly ash, blast furnace slag and obsidian added cements were measured according to TS EN 196-9. Compressive strengths of cements with obsidian, fly ash (uk) and blast furnace slag (yfc) added were measured according to TS EN 196-1.

\section{Result and Discussion}

According to TS EN 196-9, the hydration temperature of the cement decreases with increasing amount of obsidian, fly ash and blast furnace slag.In the literature, it is stated that the hydration temperature of TS EN 196-9 and 41 hours is equal to the hydration temperature measured by chemical method according to TS EN 196-8.The hydration temperature of the cement used in this study in the $41 \mathrm{st}$ hour is $250 \mathrm{j} / \mathrm{g}$ value which is equal to the hydration temperature of the cement used by Erdoğan in his study.Han et al. (2017) measured the hydration temperatures of blast furnace slag and fly ash cements at similar values. Baran and Pichniarczyk (2017) calculated values between 374 and $404 \mathrm{j}$ / $\mathrm{g}$ in CEM I 42,5 R cement. It is seen that these values are consistent with the values in this study.

In this study, the following points were determined.

1. Rize region obsidian reduces the heat of hydration of cement.

2. In terms of the hydration temperature of the obsidian, it showed similar properties with fly ash and blast furnace slag in cement.

3. The obsidian compressive strength of the Rize region is close to blast furnace slag and fly ash in cement. When used as pozzolan in obsidian cement, it has no harmful effect in terms of compressive strength. 